\title{
Development of Raffinose-Propionate Lithium Mupirocin Culture Medium, Selective for Bifidobacteria, and Evaluation of Its Association With Petrifilm ${ }^{\mathrm{TM}}$ Aerobic Count
}

\author{
Rodrigo Otávio Miranda (I), Antonio Fernandes Carvalho (I), Luís \\ Augusto Nero (I) \\ (I) UFV - Universidade Federal de Viçosa (Campus UFV, Viçosa, MG, Brazil)
}

\section{Resumo}

Fermented milks are ideal carriers of probiotic microorganisms due to their consumption and production history. The application of bifidobacteria in probiotic dairy products is usually associated with other fermenting bacteria, with the purpose of ensuring the technological and sensory qualities of the product. The mixed microbiota of fermented milks must be screened differentially with the usage of selective media to ensure the viability and concentration of the cells. Rapid alternative methodologies for the enumeration of microorganisms, like Petrifilm ${ }^{\mathrm{TM}}$, are advantageous to the food industry, but they need previous standardization. The aim of this study was to adapt selective media for bifidobacteria with Petrifilm ${ }^{\mathrm{TM}} \mathrm{AC}$ platting. Bifidobacteria, lactobacilli and streptococci strains were screened for carbohydrate fermentation profile, reduction and inhibition by 2,3,5triphenyltetrazolium chloride (TTC) and growth in selective media for bifidobacteria. Additionally, Raffinose-Propionate-MUP (RP-MUP) with conventional platting and using Petrifilm ${ }^{\mathrm{TM}} \mathrm{AC}$ with different incubation times was compared to ISO29981 methodology with TOS-MUP medium in fermented milks produced. Raffinose was the carbohydrate that presented the higher fermentation specificity by bifidobacteria, being considered for the development of alternative selective medium RP-MUP. All bifidobacteria strains were able to adequately reduce TTC, and they were not inhibited by concentration of 25, 50 and $100 \mathrm{mg} / \mathrm{L}$. TOS-MUP and RP-

\footnotetext{
Referência:

Rodrigo Otávio Miranda, Antonio Fernandes Carvalho, Luís Augusto Nero. Development of Raffinose-Propionate Lithium Mupirocin Culture Medium, Selective for Bifidobacteria, and Evaluation of Its Association With Petrifilm ${ }^{\mathrm{TM}}$ Aerobic Count. In: Anais do 12 Congresso Latinoamericano de Microbiologia e Higiene de Alimentos - MICROAL 2014 [= Blucher Food Science Proceedings, num.1, vol.1]. São Paulo: Editora Blucher, 2014.

DOI $10.5151 /$ foodsci-microal-250
} 
MUP were the culture media with best selectivity for bifidobacteria, when compared to MRS-ABC and MRS-NNLP media. RP-MUP and Petrifilm ${ }^{\mathrm{TM}}$ AC plates association allowed selective enumeration of bifidobacteria in fermented milks, with equivalent results for RP-MUP and TOS-MUP used with conventional platting methodology (ANOVA; $\mathrm{p}<0.05$ ), and high correlation indexes $(r=0.99 ; p<0,05)$, even with shorter incubation time $(48 \mathrm{~h})$. The suggested alternative protocol for the enumeration of bifidobacteria in fermented milks presented adequate performance, and represents an advantage for the usage by food industries in the quality control of probiotic products with these microorganisms.

Palavras-Chave: Bifidobacteria, Selective enumeration, Petrifilm AC, TOSMUP, RP-MUP

Agência de Fomento: CAPES, CNPq, FAPEMIG 